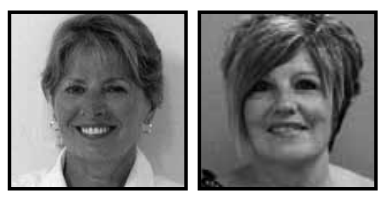

\title{
The Impact of Visual Frameworks on Teacher Candidates' Professional Reflection
}

\author{
Nancy Maynes \& Lynn Julien-Schultz, Nipissing University
}

\begin{abstract}
This study examined teacher candidates' reflections about the use of two graphic organizers referenced in their teacher education program. Fourteen themes were identified relating to teacher candidates' instructional focus; awareness of the value of the organizers to improve focus on their students' learning, growth, and independence with instructional tasks; and their focus on professional growth. Data from this study provides information to allow future comparison of teacher candidates' diversity in reflections with their teaching evaluations. Connections with brain development are identified to support the use of complex graphic organizers in professional contexts for teachers.
\end{abstract}

\section{Objectives}

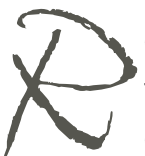

eflection on professional practice is a commonly expected element of teacher education programs. In our Faculty of Education, teacher candidates learn the skills of lesson planning and lesson delivery in curriculum methods courses. Templates are provided for teacher candidates to show them the elements of lesson planning (Schmoker, 2011). Templates require indications of the pacing of delivery for lessons. However, the linear nature of these templates does not provide the complex understanding of the elements of planning and the recursive nature of effective delivery. To support teacher candidates' understanding of the complexities and recursiveness of this task, researchers developed two graphic organizers that would provide visual support for candidates' understanding. During development these graphic organizers were subjected to the four requirements for 
conceptual representations as identified by Strauss and Corbin (1990). These graphic organizers will be explained in greater detail in the Perspectives and Theoretical Frameworks section of this paper.

This study was designed to examine teacher candidates' perceptions of the value of these graphic organizers in helping them to understand the various aspects of the planning and lesson delivery decisions they engage in during professional interaction with students. Through reflections, teacher candidates were asked to discuss the value of these graphic organizers to their internalization of concepts about lesson planning and delivery. We examined their reflections to determine the themes that were evident in their discussion and the variety of professional concepts they perceived to be evident in the graphic organizers.

\section{Perspectives and Theoretical Frameworks}

Graphic organizers provide visual representations of concepts. They can represent very complex interrelations of ideas. Organizers provide cognitive structures that support learners' ability to relate ideas and support critical thinking and higher levels of cognition (Johnson, 1990; Mayer, 1989). Holley and Dansereau (1984) explain that concepts may be more easily learned if they are presented in a non-linear fashion, as might be supported by a graphic organizer to depict elements of lesson planning and delivery. The use of graphic organizers to support comprehension has its origins in schema theory (Axelrod, 1973; Darch \& Carnine, 1986). Research also shows that the use of graphic organizers increases achievement of learning goals by 27 percent (Marzano, Pickering, \& Pollock, 2001).

Brain development is closely linked to lifelong capacity in humans. New technology has allowed scientists to examine the brain in ways that is markedly different from approaches used previously. We now know much more about both the circuitry and the neurochemistry of the brain and can make hypotheses about the impact of learning conditions on the growth, maintenance, and health of brain tissue. Current research tells us much about the brain and its capacity for learning. We know that brain development begins pre-natally and extends into adulthood (Webb, Monk, \& Nelson, 2001). The brain is specifically designed to incorporate experience into its circuitry and rewires itself to connect new experiences within its developing structure. The research presented in this paper situates new professional experiences in ways designed to create lasting schema that support the developing professional connections neurologically. 
Synapses between neurons of the brain and between neurons and the insulating material, called myelin, expand with experiences. Myelin allows the brain impulses to be conducted rapidly among neurons (Craik \& Bialystok, 2006; Webb et al., 2001). A richer learning environment, as provided by resources that support conceptual connections in learning new ideas, and more learning opportunities, increase both synapses and myelin (Thomas \& Johnson, 2008; Knudsen, 2004). As the brain learns to create more efficient networks and connections, synaptic pruning occurs and decreases the number of neural connections in favour of the most efficient neural connections (Greenough, Black, \& Wallace, 1987). The brain is remarkably resilient (Barinaga, 2000; Bruner, 1999). The ability to grow professional concepts through resources designed to help learners make connections can be thought to support the learner's thinking and improve efficiency in recall.

Using this rationale we designed two graphic organizers to help teacher candidates understand the complexities of lesson-planning concepts. The use of these graphic organizers is supported by research into the impact of graphic organizers on the users' ability to relate and retain knowledge and differentiate among the key concepts (in this case the phases of instruction) and related concepts (in this case, aspects of support and assessment that should be available to learners as they engage each phase of instruction) (Hall, Hall, \& Saling, 1999).

The first organizer presents a graphic depiction of the phases of instruction. Details of this graphic representation are presented in another paper (Maynes, JulienSchultz, \& Dunn, 2010b) and research related to the application of this model has also been reported in another article (Maynes, Julien-Schultz, \& Dunn, 2010a) (see figure 1). 


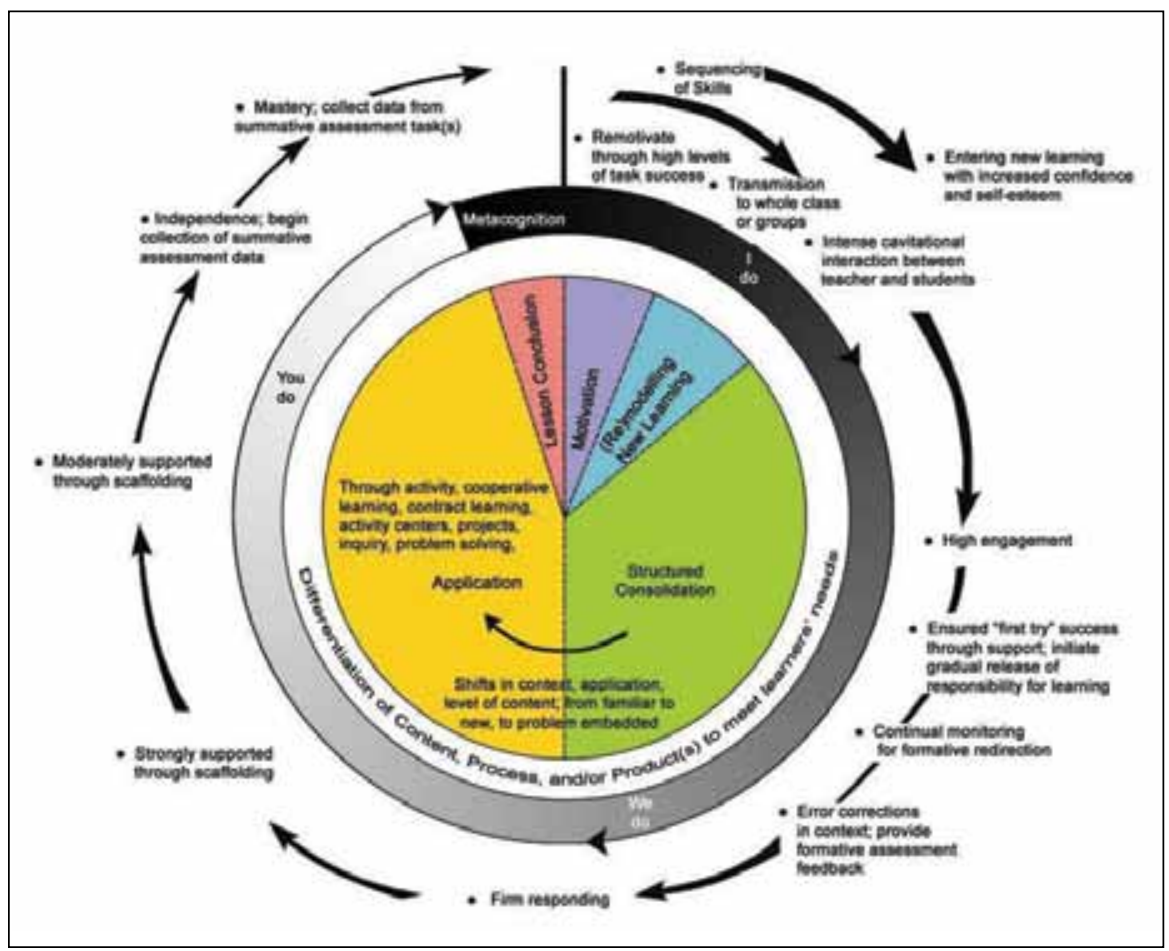

Fig. 1: Graphic representation of teacher actions related to the phases of instruction

As this diagram was used for instructional purposes with teacher candidates it became evident that they needed further support to understand the concepts of the gradual release of responsibility (Fisher \& Frey, 2008), differentiated instruction (Tomlinson, 1999), and the different uses of assessment for, as and of learning (Earl, 1995; Earl, 2003). A second graphic organizer was developed to support understanding of these concepts. This organizer used the teacher's voice to represent the professional thinking that the teacher would engage in while planning and delivering phases of a lesson (see figure 2). In this organizer the elements of assessment are the focus. 


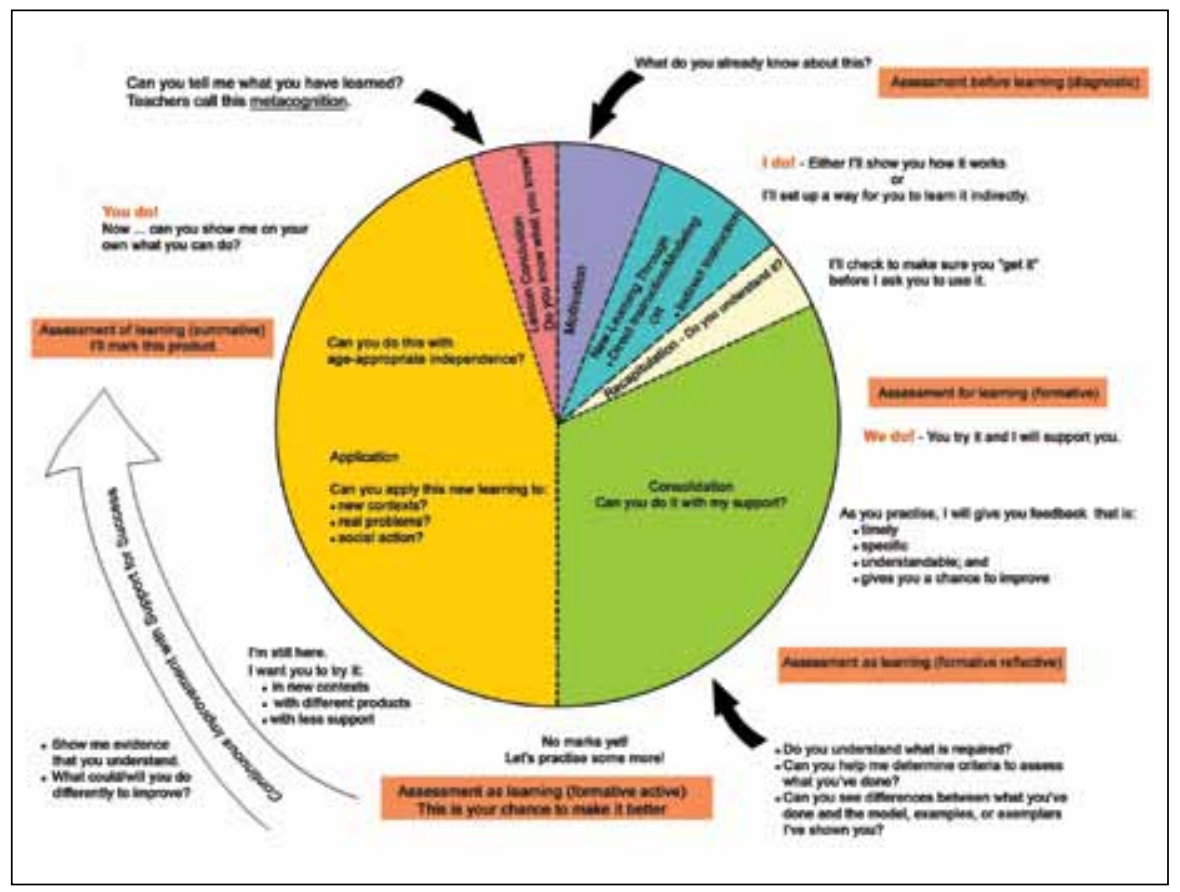

Fig. 2: Understanding the gradual release of responsibility, differentiated instruction, and the different uses of assessment

After using these graphic organizers (figures 1 and 2) with teacher candidates we were interested in examining their perceptions of the value of these organizers to advance their professional thinking.

Schema theory (Axelrod, 1973) holds that a highly accessible schema is checked for understanding before a less accessible schema (i.e., a lesson planning template) is attempted. The graphic organizers are much more accessible than the linear template. Since the visual graphics provide access to the thinking embedded in both direct and indirect modes of instruction, they provide schema that allow teacher candidates to create an available fit to the other information about their professional roles of planning and instruction. If the graphics are known to work for this purpose, teacher candidates should develop more confidence in their ability to apply the general visuals (schema) across contexts. Complex schema also reduces memory requirements because teacher candidates are able to interpret separate bits of information about a current lesson in terms of the parameters of the general schema of either organizer, as consistent with schema theory. The credibility of the figures should be 
enhanced when the teacher candidates are able to apply them to many lesson instances so they can see the generalizability of the graphic representations.

As in the general theory of schema use, teacher candidates should see the graphics as readily adaptable if they support their interpretation of the needs for a lesson plan or its delivery. For example, a teacher candidate might decide that the consolidation time for a specific skill needs to be greater than the diagrams indicate visually. These graphics readily allow for such adaptation to cases as indicated by the dotted lines between wedges.

Schema theory also holds that a common error in recalling an experience is to recall the part that is compatible with the existing schema and to forget or discard the part that does not fit (Axelrod, 1973). By providing teacher candidates with figures 1 and 2 we theorize that teacher candidates have fewer opportunities to reduce their schema to more simplistic boundaries and must explore the lesson's complex nature more thoroughly.

Finally, each teacher candidate's cognitive style may be reflected in the value he or she sees in the graphic organizers central to this study. In the course context where these visual organizers were used, verbal support was also provided for learning the same skills. By making use of the graphics to support the verbal instruction, the teacher candidates' cognitive style is supported (Mayer \& Massa, 2003).

\section{Modes of Inquiry}

Teacher candidates complete a number of assignments that provide evidence of their learning in the teacher education program. One of these assignments asked them to reflect on their perception of the value of the two organizers presented in figures 1 and 2 . This reflection was subsequent to components of the assignment where teacher candidates were required to develop a lesson plan and reflect on it. These reflections were analyzed by researchers to identify themes that were included (Creswell, 2002).

Forty-three teacher candidates participated in providing access to their reflective writing. Teacher candidates wrote an average of 330 words in their reflection pieces. The median length of reflections was 351 words. A random sample of 20 percent of the teacher candidates' reflective writing was checked by a second researcher 
to establish inter-rater reliability of the coding process. Both the presence and incidence of each theme was recorded on data charts.

The initial question for this research project was: "What themes will emerge from teacher candidates' reflective writing about the value of two graphic organizer diagrams designed to support their developing conceptions about lesson planning and delivery?" As data was examined, specific questions related to the examination of data and trends revealed by it emerged. These questions included: 1) Which of the emerging themes appeared to be major themes and which appeared to be minor themes? 2) How many of the themes identified by any of the respondents appeared in each respondent's reflections? 3) Did the discrete themes we initially identified cluster into broader themes? and 4) What was the frequency of mention of each theme cluster in teacher candidates' reflective writing?

The first analysis of teacher candidate reflections revealed 14 categories (see figure 3) of themes that they identified as professional ideas attributed to being internalized because of learning the concepts embedded in the graphic organizers (their professional schema). Writing samples were analyzed to determine the percentage of occurrence of each of the fourteen themes. Many themes were evident in the writing of a number of students so it was decided to sort these recurrent themes into the categories of "minor themes" and "major themes." Any theme that occurred in more than $30 \%$ of the teacher candidates' reflections was categorized as a major theme. Thirty percent was decided upon as a criterion to be considered a major theme because there was a significant decrease in the incidence of some data categories (themes) below those that appeared in $34 \%$ of the writing samples.

We then considered the number of themes mentioned by each candidate. It was evident in some writing samples that several themes were mentioned while other teacher candidates reiterated and developed only a few themes (see figure 5). Once the number of themes was identified researchers decided that it would be valuable to sort themes to determine relationships among themes. By sorting the 14 themes into clusters, three theme clusters were identified (see figure 6). Once theme clusters were evident we reexamined the reflective writing samples and sorted the responses into the three theme clusters to determine the number of reflections related to each cluster.

Examination of the incidence of writings in relation to each theme cluster revealed that one cluster of reflections was more dominant in teacher candidates' writing than the other two clusters. When this was realized we reanalyzed the data to determine the incidence of mention of each theme cluster (see figure 7). 


\section{Data Analysis}

The 14 themes that emerged from teacher candidates' reflective writing included: understanding planning conceptions, understanding instructional conceptions, time management, support for professional reflection, understanding the gradual release of responsibility, understanding variations of practice for consolidation and application, understanding relationships between successful practice and successful modeling before practice, understanding transitions within phases, framework to support continuous professional growth, knowing when to use various forms of assessment, support to help teachers see opportunities for differentiation, developing students' metacognitive awareness, celebrating evidence of learning and readiness to apply, and understanding that students' success within any phase of instruction influences potential for success in the next phase.

\begin{tabular}{|c|c|}
\hline Dominant Themes & Minor Themes \\
\hline $\begin{array}{l}\text { - Understanding Planning Conceptions } \\
\text { - Understanding Instructional Conceptions } \\
\text { - Time Management } \\
\text { - Support for Professional Reflection } \\
\text { - Understanding the Gradual Release of } \\
\text { - Understanding Variations of Practice for } \\
\text { - Understanding Relationships between } \\
\text { - Successful Practice and Successful } \\
\text { - Undeling Before Practice } \\
\text { - Framework to Support Continuous } \\
\text { - Professional Growth } \\
\text { - Anowing When to Use Various Forms of } \\
\text { Asscssment }\end{array}$ & $\begin{array}{l}\text { - Support to Help Teachers "See" } \\
\text { Opportunities for Differentiation } \\
\text { - Developing Students' Metacognitive } \\
\text { Awareness } \\
\text { - Celebrating Evidence of Learning and } \\
\text { Readiness to Apply } \\
\text { - Understanding that Suceess within and } \\
\text { Phase Influences Potential for Success in } \\
\text { the Next Phase }\end{array}$ \\
\hline
\end{tabular}

Fig. 3: Themes that emerged from the qualitative analysis of students' assignments

Figure 4 shows the percentage of teacher candidates' reflective writing related to each of the themes. Some categories of reflection showed very high incidence among the teacher candidates' reflective writing. This is consistent with literature related to the use of frameworks for organizing information. Where goals are clear (i.e., to learn how to plan and deliver lessons effectively), learners have been shown to make use of more mature and effective techniques for reaching the goals (Garner, 1990). In this case, teacher candidates indicated that the use of these visual frameworks supported their goal-related access to the complex interconnection of ideas about lesson planning and delivery. 


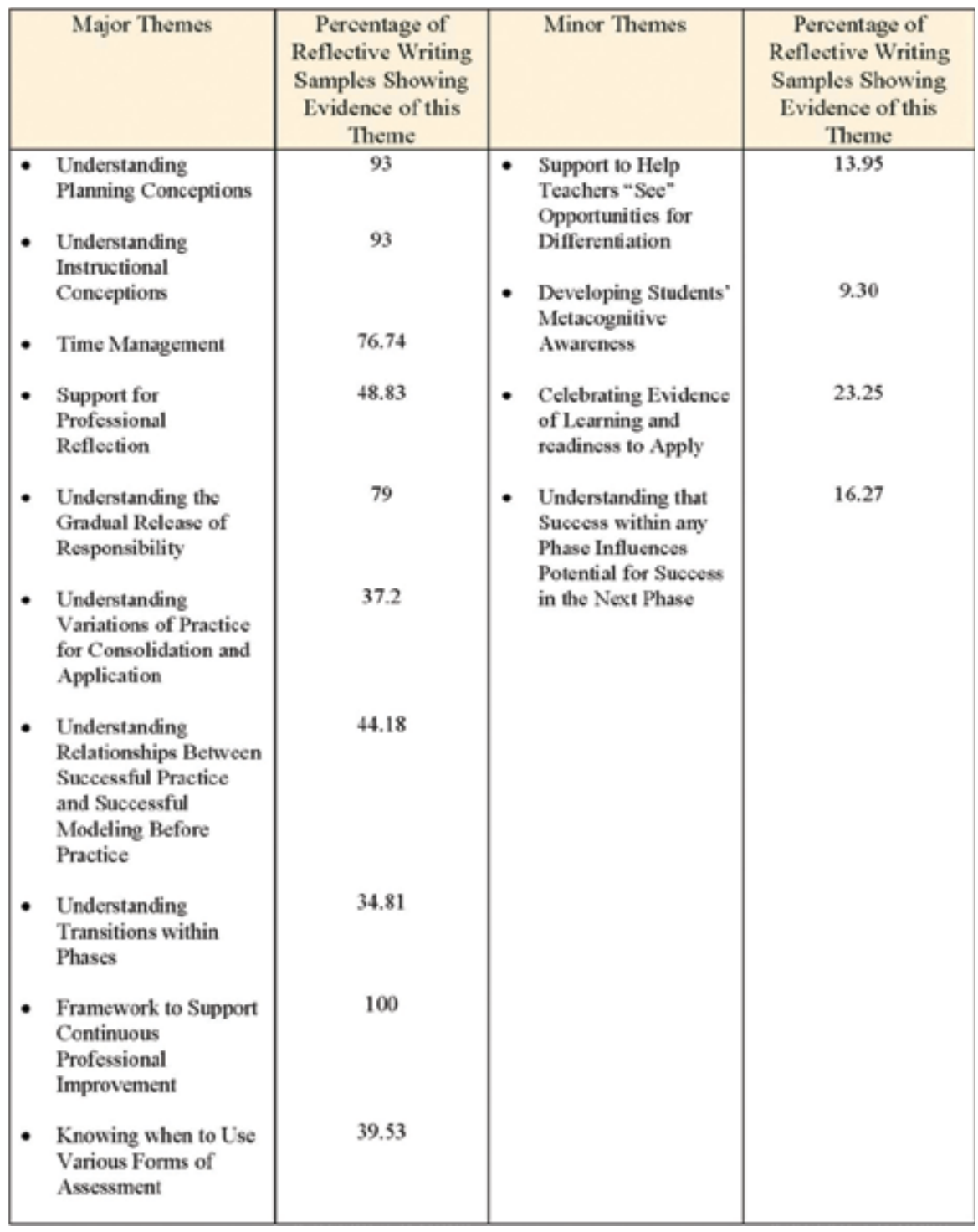

Fig. 4: Percentage of students who showed evidence of reflections related to the emerging themes in their writing 
Teacher candidate responses were also analyzed to determine the typical number of themes mentioned by any candidate. No teacher mentioned all 14 of the themes that emerged from the group. Twenty-nine of the teacher candidates addressed between six and eight themes in their reflective writing (see figure 5). This diversity is indicative of richness of understanding of the complexities represented in the diagrams.

\begin{tabular}{|c|c|}
\hline $\begin{array}{c}\text { Possible Number of Themes that Could be } \\
\text { Mentioned }\end{array}$ & $\begin{array}{c}\text { Number of Teacher Candidates }(\mathrm{N}=43) \text { who } \\
\text { Mentioned this Total Number of Themes in Their } \\
\text { Reflection }\end{array}$ \\
\hline 1 & 0 \\
\hline 2 & 0 \\
\hline 3 & 3 \\
\hline 4 & 1 \\
\hline 5 & 4 \\
\hline 6 & 12 \\
\hline 7 & 10 \\
\hline 8 & 7 \\
\hline 9 & 2 \\
\hline 10 & 3 \\
\hline 11 & 1 \\
\hline 12 & 0 \\
\hline 13 & 0 \\
\hline 14 & 0 \\
\hline & \\
\hline & \\
\hline
\end{tabular}

Fig. 5: Number of themes mentioned by teacher candidates

No teacher candidate addressed less than three themes in their reflective writing. Eleven of the 14 themes was the maximum number addressed by any one sample of reflective writing.

We examined connections among the 14 themes that were evident in their writing by asking, "What do certain themes in the writing have in common?" All 14 themes could be catalogued into one of three overall clusters. Teacher candidates' reflective writings were focused on 1) their instruction as a teacher, 2) the learning, growth, and increasing levels of independence of the students they taught, or 3) their professional growth as educators (see figure 6). These clusters represent both knowledge and cognitive processes in a professional context (Brown, 1988; Glaser, 1984; McKeachie, 1988; Rabinowitz, 1988). Each theme cluster includes background conceptions that teacher candidates explained as their understandings related to the conceptual diagrams (knowledge) and the guidance they perceived for professional action during lesson delivery (cognitive processes). 


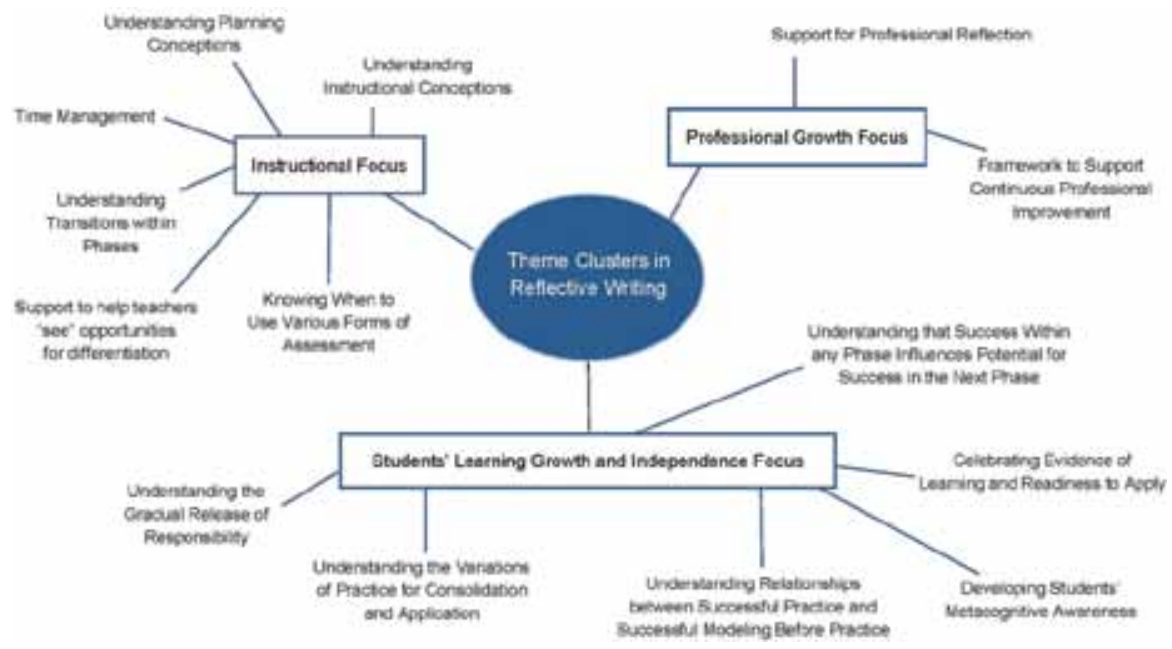

Fig. 6: Theme clusters in the teacher candidates' reflections

We then considered the question, "How often was each of these three theme clusters evident in reflections?"We calculated the frequency of teacher candidates addressing each cluster in their reflective responses (see figure 7). 


\begin{tabular}{|c|c|c|}
\hline Instructional Focus Cluster & $\begin{array}{l}\text { Professional Growth Focus } \\
\text { Cluster }\end{array}$ & $\begin{array}{l}\text { Learning Growth and } \\
\text { Independence Focus }\end{array}$ \\
\hline $\begin{array}{l}\text { Including : Understanding } \\
\text { planning conceptions, } \\
\text { understanding instructional } \\
\text { conceptions, time } \\
\text { management, understanding } \\
\text { transitions within phases, } \\
\text { support to help teachers see } \\
\text { opportunities for } \\
\text { differentiation, and knowing } \\
\text { when to use various forms of } \\
\text { assessment }\end{array}$ & $\begin{array}{l}\text { Including: Support for } \\
\text { professional reflection, and a } \\
\text { framework to support } \\
\text { continuous professional } \\
\text { improvement }\end{array}$ & $\begin{array}{l}\text { Including: Understanding the } \\
\text { gradual release of } \\
\text { responsibility, understanding } \\
\text { variations of practice for } \\
\text { consolidation and application, } \\
\text { understanding relationships } \\
\text { between successful practice } \\
\text { and successful modeling } \\
\text { before practice, developing } \\
\text { students' metacognitive } \\
\text { awareness, celebrating } \\
\text { evidence of lcarning and } \\
\text { readiness to apply, and } \\
\text { understanding that success } \\
\text { within any phase influences } \\
\text { potential for success in the } \\
\text { next phase }\end{array}$ \\
\hline $\begin{array}{l}\text { Understanding planning } \\
\text { conceptions }=86\end{array}$ & $\begin{array}{l}\text { Support for professional } \\
\text { reflection }=17\end{array}$ & $\begin{array}{l}\text { Understanding the gradual } \\
\text { release of responsibility }=72\end{array}$ \\
\hline $\begin{array}{l}\text { Understanding instructional } \\
\text { conceptions }=104\end{array}$ & $\begin{array}{l}\text { Framework to support } \\
\text { continuous professional } \\
\text { development }=173\end{array}$ & $\begin{array}{l}\text { Understanding variations of } \\
\text { practice for consolidation and } \\
\text { application }=18\end{array}$ \\
\hline Time management $=68$ & & $\begin{array}{l}\text { Understanding relationships } \\
\text { between successful practice } \\
\text { and successful modeling } \\
\text { before practice = } 34\end{array}$ \\
\hline $\begin{array}{l}\text { Understanding transitions } \\
\text { within phases }=28\end{array}$ & & $\begin{array}{l}\text { Developing students' } \\
\text { metacognitive awareness }=4\end{array}$ \\
\hline $\begin{array}{l}\text { Support to help teachers see } \\
\text { opportunities for } \\
\text { differentiation }=7\end{array}$ & & $\begin{array}{l}\text { Celebrating evidence of } \\
\text { learning and readiness to } \\
\text { apply=16 }\end{array}$ \\
\hline $\begin{array}{l}\text { Knowing when to use various } \\
\text { forms of assessment }=27\end{array}$ & & $\begin{array}{l}\text { Understanding that success in } \\
\text { any phase influences potential } \\
\text { for success in the next phase= } \\
16\end{array}$ \\
\hline
\end{tabular}

Fig. 7: Theme cluster frequency

By examining the clusters of related themes we were able to determine the concentration of focus within these reflections. This data showed that teacher candidates addressed instructional foci 320 times in the samples (40.7\%). Students' learning and growth was mentioned 160 times in the reflections (23.8\%). Reflective writing samples focused on the teacher candidates' professional growth 190 times in the writing samples (28.3\%). Teacher candidates' reflections focused most frequently on their instructional actions, next most frequently on their professional growth, and least frequently on their students' learning and growing independence with new learning. 


\section{Discussion}

Lesson planning and delivery are major skills for teachers. In faculties of education teacher candidates often learn these skills by completing templates that are essentially linear. Such templates embed many instructional conceptions that need to be learned by teachers. However, because of the linear nature of templates, they may not allow teacher candidates to consider the intricacies and recursive nature of the decisions they need to make as they plan and deliver lessons (Schmoker, 2011). Such templates may not allow teacher candidates to make connections among the elements of lesson planning and delivery that are known to influence learning (Cochran-Smith, Gleeson, \& Mitchell, 2010; Noell \& Burns, 2009).

Conceptual diagrams are not constrained by linear representations. They can be used to help teacher candidates visualize the intricacies and relationships of planning and lesson delivery (knowledge) and to internalize a dynamic visual model for the elements they need to address in their planning and delivery roles (processes). Through the use of dynamic visual models for the processes, teacher candidates can learn to be less prescriptive and more intuitive in the way they manage planning and instruction. Visual models that are the focus of this study incorporate fluid knowledge of many interrelated elements of planning. The two models presented in this paper connect concepts related to planning, delivery, differentiated instruction, timing, gradual release of responsibility, assessment and evaluation types and processes, the nature of applications, and student success. By understanding the interconnectedness of these elements teacher candidates were able to reflect upon the graphic representations as they related to their instructional focus, their focus on students' learning and increasing independence, and the teacher candidates' professional growth.

This analysis allowed us to see that the reflective writing is less student focused than we would hope to have seen, with less than one quarter being focused on reflecting about the students' learning outcomes related to their teachers' improved understanding of professional concepts. Instructionally focused reflections were almost twice as likely to be mentioned as either professional growth or students' learning and growth foci. This suggests that teacher candidates still have a fairly mechanical view of the conceptual models rather than seeing the models as supports to help them optimize their focus on student learning.

Teacher candidates' reflective writing showed many benefits of the supplemental use of the two graphic organizers to support their understanding of professional concepts. They are using the two organizers to support both practice and 
reflection on practice. All teacher candidates said that they could either visualize the graphic organizers as they planned and delivered lessons or they kept the paper copies of each close as they planned. Many said that they used the organizers to support planning in a whole-to-part manner as they approached planning and delivery. They could "see" the whole lesson before they started to write about each part of their plan in the planning template that is prescribed in their program. They saw the graphic organizers as supports for their developing professional schema.

Many teacher candidates spoke about sharing the graphic organizers with others, including their associate teachers, parents who were teachers, or other teacher candidates they met socially or on placements. This sharing activity is indicative of the value they saw in the organizers. The ability to use the organizers to imagine the progress of a lesson seemed to allow most of the teacher candidates to develop a sense of how to manage the allotted lesson time more effectively than they might have without these supports. The brightly coloured wedges and shading in the concentric circles (see figure 1) was seen by teacher candidates as helping them internalize the concept of the gradual release of responsibility as lessons progressed. Teacher candidates seemed to develop a sense of the various forms of assessment and relate these forms of assessment to the many uses of assessment for, as, and of learning.

Major findings of this study include three main ideas. First, this study has provided sound confirmation of the validity of the reflective writing process to have teacher candidates examine their own internalization of professional concepts. Written reflections evidently supported the connection-making process, consistent with brain research. In all reflective responses it was evident that teacher candidates found value in engaging in professional reflection that was supported by having comprehensive conceptual diagrams that organized and related many lesson planning and delivery theories.

Second, teacher candidates expressed unanimous appreciation of the conceptual diagrams in their reflective responses. They identified that the diagrams helped them connect many concepts related to their professional roles and to relate the ideas in the diagrams to their professional conversations. They expressed the value of the diagrams as summative models that pulled ideas together for them.

Third, it is evident that even with the support of comprehensive conceptual diagrams most teacher candidates have not developed a perspective on their professional role that allows them to shift their thinking from focusing on their teaching duties toward focusing on students' learning, as shown in the incidence of writing 
about the learning growth and independence cluster (see figure 6). While this shift was evident in $9 \%$ of reflective responses, we consider this to be a remarkably low return in understanding given the purpose of the graphic organizers. Although this concept was mentioned 160 times in the 43 writing samples, it was the weakest of the three reflective writing theme clusters that were identified in teacher candidates' writing.

It may be that we, as researchers, see the three clusters of reflections in a hierarchical manner. If we consider the instructional focus to be the focus most likely to appear immediately in teachers' professional development, and their focus on professional growth to be the next most likely as they end their professional preparation program and begin searching for a job, we gain some perspective on why their focus on students' growth was the weakest of the three areas of reflection in their writing. This sequence may simply reflect the realities of their stage of development within the profession. From this perspective, it is perhaps rewarding to see as much focus on students' learning as was evident in the reflective writing. This may indicate that there is a sequence in the thinking of teacher candidates that leads them to focus first on what they do as teachers, next on what they can do to improve, and finally on what they can do to support their students' learning more effectively. If this is a predictable sequence of foci as teacher candidates mature as professionals, it will have implications for professional preparation programs. If we can make this sequence of foci visible to teacher candidates and to their professors, we can provide more specific attention to each area of development and pursue development of focus on students' learning more intentionally.

Further parallel study is underway to examine the professional characteristics and dispositions of teachers who make this shift in their thinking (Maynes \& Hatt, 2011).

The focus on instructional actions rather than on student learning in professional reflections may partially be accounted for by the theory of settings (Garner, 1990). This theory suggests that learning strategies may vary when the context of use and need vary. Since the teacher candidates were making use of these visual frameworks in the context of assignment and testing reflections, rather than in actual preparation for classroom instruction, their focus within the reflections may have been influenced by the context of strategy use. Much more focus on student learning in actual reflections might have been evident if teacher candidates had actually taught the lesson and were reflecting on its success. If the nature of the strategic reflective activity varies with context we might expect teacher candidates to be less vigilant 
about the nature of their reflections when their professional tasks result in more duties and responsibilities and less time to complete them. Differential strategy use by setting is well documented in research literature (Garner, 1990). We have no reason to suspect that general findings about strategy use would not also apply to teacher candidates' use of the visual organizers to support their planning and lesson delivery. Evaluation on one's knowledge is essentially a metacognitive activity. There is no doubt that teacher candidates found the visual models to be valuable in helping them to understand the concepts that underlay the complex processes of lesson planning and delivery. The diversity of key ideas they attribute to their understanding of these models is evident from this study. Because these visual models support access to complex elements that interrelate one's knowledge of learning to plan and deliver lessons, we can expect that these models will continue to be valued as professional tools.

This study informs our practice as teacher educators. Awareness of the key messages that teacher candidates have taken away from their personal use of these graphic models may also help us attend to highlighting embedded messages more effectively. In our future use of these organizers we can address Garner's theory of settings (1990) more directly to make teacher candidates aware that some aspects of these organizers may have more relevance at different stages in their development as professionals. We can emphasize the value of these organizers as frameworks to support students' learning.

Future research will seek to identify possible alignment between the diversity in teacher candidates' reflective writing about planning and lesson delivery concepts and evaluations of their teaching skills.

\section{References}

Axelrod, R. (1973). An information processing model of perception and cognition. The American Political Science Review, 67(4), 1248-1266.

Barinaga, M. (2000). A critical issue for the brain. Science (288), 2116-2119.

Brown, A.L. (1988). Motivation to learn and understand: On taking charge of one's own learning. Cognition and Instruction, 5, 311-321.
Bruner, J. (1999). The myth of the first three years: A new understanding of early brain development and lifelong learning. New York: Free Press.

Cochrane-Smith, M., Gleeson, A., \& Mitchell, K. (2010). Teacher education for social justice: What's pupil learning got to do with it? Berkley Review of Education, 1(1), 35-61. 
Craik, F., \& Bialystok, E. (2006). Cognition through the lifespan: mechanisms of change. Trends in Cognitive Science, (10), 131-138.

Creswell, J.W. (2002). Educational research: Planning, conducting, and evaluating quantitative and qualitative research. Upper Saddle River, N.J: Merrill Prentice Hall.

Darch, C., \& Carnine, D. W. (1986). Teaching content area material to learning disabled students. Exceptional Children, 53, 240-246.

Earl, L. (2003). Assessment as learning: Using classroom assessment to maximize student learning. Thousand Oaks, CA: Corwin.

Earl, L.M. (1995). Assessment and accountability in education in Ontario. Canadian Journal of Education, 20(1), 45-55.

Fisher, D., \& Frey, N. (2008). Releasing responsibility: Giving students ownership of learning. Educational Leadership, 66(3).

Garner, R. (1990). When children and adults do not use strategies: Toward a theory of settings. Review of Educational Research, 60(4), 517-529.

Glaser, R. (1984). Education and thinking: The role of knowledge. American Psychologist, 39, 93-104.

Greenough, W., Black, J., \& Wallace, C. (1987). Experience and brain development. Child Development, (58), 539-559.

Hall, R., Hall, M., \& Saling, C. (1999). The effects of graphical postorganization strategies on learning from knowledge maps. The Journal of Experimental Education, 76(2), 101-112.

Holley, C., \& Dansereau, D. (1984). Spatial learning strategies. New York: Academic Press.

Johnson, L. (1990). Learning across the curriculum with creative graphing. The Reading Teacher, 36(6), 492-496.

Knudsen, E.I. (2004). Sensitive periods in the development of the brain and behavior. Journal of Cognitive Neuroscience, 16(8), 1412-1425.

Marzano, R., Pickering, D., \& Pollock, J. (2001). Classroom instruction that works: Researchbased strategies for increasing student achievement. Association for Supervision and Curriculum Development, VA.
Mayer, R. (1989). Models for understanding. Review of Educational Research, 59, 43-64.

Mayer, R., \& Massa, L. (2003). Three facets of visual and verbal learners: Cognitive ability, cognitive style, and learning preference. Journal of Educational Psychology, 95(4), 833-846.

Maynes, N., \& Hatt, B. (2011). The continuum of teacher preparation: Focused growth or diffused efforts? Paper presented at AERA Conference, New Orleans, LA.

Maynes, N., Julien-Schultz, L., \& Dunn, C. (2010a). Managing direct and indirect instruction: A visual model to support lesson planning in pre-service programs. The International Journal of Learning.

Maynes, N., Julien-Schultz, L., \& Dunn, C. (2010b). Modeling and the gradual release of responsibility: What does it look like in the classroom? Brock Journal, 19(2), 65-77.

McKeachie, W.J. (1988). The need for study strategy training. In C.E. Weinstein, E.T. Gietz, \& P.A. Alexander (Eds.), Learning and study strategies: Issues in assessment, instruction, and evaluation. San Diego: Academic, 3-9.

Noell, G., \& Burns, J. (2006). Value-added assessment of teacher preparation: An illustration of emerging technology. Journal of Teacher Education, 57(1), 37-50.

Rabinowitz, M. (1988). On teaching cognitive strategies: The influence of accessibility of conceptual knowledge. Contemporary Educational Psychology, 13, 229-235.

Schmoker, M. (2011). Focus: Elevating the essentials to radically improve student learning. Alexandria, VA: ASCD.

Strauss, A., \& Corbin, J. (1990). Basics of qualitative research: Grounded theory procedures and techniques. Thousand Oaks: CA. Sage Publications, Inc.

Tomlinson, C. (1999). The differentiated classroom: Responding to the needs of all learners. Alexandria, VA: ASCD.

Webb, S., Monk, C., \& Nelson, C. (2001). Mechanisms of postnatal neurobiological development: Implications for human development. Developmental Neuropsychology (19), 147-171. 


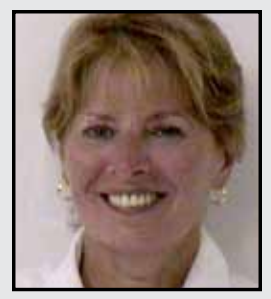

Nancy Maynes is an Assistant Professor at the Schulich School of Education at Nipissing University in North Bay. After a career in public education and administration, she joined the university in 2006. She has chaired the Concurrent Education Program (2008-2011) and has authored several books about education, including Social Studies: Innovative Approaches for Teachers; Kindergarten in Canada: A Play-Based Approach for Educators; and Focus on Learning: The Art and Science of Planning, Delivering, and Assessing Effective Lessons.

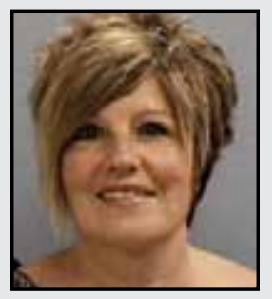

Lynn Julien-Schultz is an Assistant Professor at the Schulich School of Education at Nipissing University in North Bay. Lynn has been a teacher, guidance counselor, program coordinator, and administrator for over 30 years and has now been at the university full time for the past four years. Her expertise has been in programs for youth at-risk, assessment and evaluation, curriculum development, and leadership. Her publications have been in the areas of instructional pedagogy and international experiences.

\section{LINKTO:}

http://hdap.oise.utoronto.ca

http://www.nipissingu.ca/faculty/nancym/ 